\title{
Desafios dos programas compliance nas empresas públicas
}

\author{
Compliance program challenges in public enterprises
}

Tiago Antunes Rezende ${ }^{1}$

\begin{abstract}
Resumo: O presente trabalho tem como objeto de estudo os programas compliance aplicável às empresas públicas brasileiras. Outrossim, objetiva analisar quais são os instrumentos para o desenvolvimento e a implantação dos programas de conformidade pelas empresas públicas pertencente à Administração Pública indireta. Para isso, utiliza-se o método hipotético-dedutivo, mediante um estudo bibliográfico e legislação pertinente ao tema. Como marco teórico inicial, adota-se a teoria do ato administrativo, pois a criação de uma empresa pública deve ser autorizada por lei. Como hipótese inicial, compreende-se a possibilidade de as empresas públicas desenvolverem e implantarem programas compliance considerando as regras de governança corporativa disciplina na Lei $\mathrm{n}^{0}$ 13303/2016, também conhecida como Lei das Estatais.
\end{abstract}

Palavras-chave: Programas Compliance; Empresas Públicas; Governança Corporativa; Administração Pública.

\begin{abstract}
The present work has as object of study the compliance programs applicable to Brazilian public companies. Furthermore, it aims to analyze the instruments for the development and implementation of compliance programs by public companies belonging to the indirect public administration. For this, the hypothetical-deductive method is used, using a bibliographic study and legislation pertinent to the theme. As an initial theoretical framework, the Theory of Administrative Act is adopted, since the creation of a public company must be authorized by law. As an initial hypothesis, it is understood the possibility for public companies to develop and implement compliance programs considering the rules of corporate governance discipline in Law No. 13303/2016, also known as the state law.

Keywords: Compliance Programs; Public companies; Corporate governance; Public administration.
\end{abstract}

\section{Introdução}

O objetivo principal deste artigo é analisar o desenvolvimento e a implantação dos programas compliance nas empresas públicas brasileiras. Ademais, possui como objetivo específico realizar um estudo aprofundado

\footnotetext{
${ }^{1}$ Professor da Universidade Cruzeiro do Sul - UNICSUL/SP. Mestre em Direito na linha de Justiça, Empresa e Sustentabilidade pela Universidade Nove de Julho - UNINOVE. Pósgraduado Lato Sensu em Direito do Trabalho e Processo do Trabalho pelas Faculdades Metropolitanas Unidas - FMU. Diretor de Instituições Públicas da Federação Nacional de Pós-graduandos em Direito - FEPODI.
} 
sobre os programas compliance a partir da análise dos relatórios expedidos pelo Departamento de Coordenação e Governança das Empresas Estatais (DEST), Órgão responsável pelas Empresas Públicas Federais.

A problemática da pesquisa verifica-se no seguinte questionamento: as empresas públicas estão pautadas nos princípios da Administração Pública para implantarem os programas compliance?

Para isso, adota-se o método hipotético-dedutivo mediante análise bibliográfica e legislação pertinente ao tema para chegar a uma conclusão cientificamente válida. Assim, como marco teórico inicial deste trabalho adota-se a teoria do ato administrativo para determinar categoria de atos no exercício da função pública.

Como justificativa dessa pesquisa, ressalta-se que após edição da Lei da $\mathrm{n}^{\mathrm{o}}$ 12.846/2013, a qual incentivou o desenvolvimento e a implantação dos programas compliance nas empresas privadas houve a necessidade de editar a Lei $\mathrm{n}^{0} 13.303 / 2016$ para que as empresas públicas também pudessem desenvolver e implantar programas de comprometimento, considerando o êxito desse instrumento mitigador de atos de corrupção no setor privado.

Pode sustentar-se que as empresas públicas devem ter por objetivo geral eliminar eventuais riscos da atividade empresarial, criando mecanismos propícios de combate à corrupção. Com efeito, é fundamental o desenvolvimento e a implantação dos programas compliance nas empresas públicas para que não haja desvios de recursos públicos nas estatais.

Diante disso, observa-se que o presente estudo é de suma importância para o Direito Administrativo, pois é necessário o debate jurídico sobre a necessidade de as empresas públicas combaterem atos de corrupção no âmbito interno da organização. Portanto, o trabalho é divido em três partes para aprofundar os estudos sobre os programas compliance nas estatais, consoante a gestão pública de recursos.

$\mathrm{Na}$ primeira parte deste trabalho analisarei a consolidação das empresas públicas após a promulgação da Constituição Federal de 1988, 
ressaltando as principais características, contradições e avanços na esfera pública. Ademais, também demonstrarei a evolução das empresas públicas federais nos últimos cinco anos.

Outrossim, na segunda parte deste trabalho analisarei o surgimento dos programas compliance no setor privado, bem como a possibilidade jurídica de sua aplicação nas empresas públicas. Nesse sentido, também realizei um estudo sobre os principais desafios para o desenvolvimento e a implantação dos programas de conformidade legal nas estatais.

Por fim, na terceira parte analisarei o programa compliance nas empresas públicas, pautado na Lei $\mathrm{n}^{\circ} 13.303 / 2016$, no que tange aos aspectos fundamentais do novo modelo de gestão pública, destacando também os atuais parâmetros legais que devem ser observados pelo programa de conformidade aplicável às estatais.

\section{Consolidação das empresas públicas no Brasil}

A Constituição Federal de 1998 consagrou às pessoas jurídicas de direito privado no âmbito da Administração Pública indireta a expressão empresas estatais, cujo Estado possua o controle acionário. Importante mencionar que a expressão alcança as empresas públicas, apesar da personalidade de direito privado.

Para Di Pietro, com a expressão empresa estatal ou governamental designamos todas as entidades, civis ou comerciais, de que o Estado tenha o controle acionário, abrangendo a empresas públicas, a sociedade de economia mista e outras empresas que não tenham essas naturezas e às quais a Constituição faz referência, em vários dispositivos (DI PIETRO, 2001, p.454).

Assim, pode dizer que empresas públicas é entidade dotada de personalidade jurídica de direito privado, a qual possui o patrimônio próprio com capital exclusivo do Estado, com o objetivo de prestar serviço público, 
bem como exploração da atividade econômica, sendo autorizadas por lei específica.

\begin{abstract}
A Emenda Constitucional $n^{\circ} 19 / 98$ corrigiu uma falha do artigo 37, XIX, da Constituição, que exige lei específica para a criação de empresa pública, sociedade de economia mista, autarquia ou fundação. O dispositivo era criticado porque em se tratando de entidades de direito privado, como a sociedade de economia mista, a empresa pública e a fundação, a lei não cria a entidade, tal como faz com a autarquia, mas apenas autoriza a criação, que se processa por atos constitutivos do Poder Executivo e transcrição no Registro Público. Com a nova redação, a distinção feita, estabelecendo o referido dispositivo que somente lei específica poderá ser criada autarquia e autorizada a instituição de empresa pública, de sociedade de economia mista e de fundação, cabendo à lei complementar, neste último caso, definir as áreas de sua autuação (DI PIETRO, 2001, p.458).
\end{abstract}

Nessa perspectiva, as empresas públicas criadas mediante autorização de lei específica, com natureza jurídica de direito privado, serão regidas pelo artigo 173 da Constituição Federal, bem como pelo Código Civil no que for compatível. Desse modo, à instituição das empresas públicas submeterá a um procedimento de fases, que envolvem a promulgação da lei que autoriza a criação da entidade, expedição de decreto e por fim o registro dos atos constitutivos no cartório.

No entanto, para Flávia Cristina Moura de Andrade, a lei autoriza o Poder Executivo a, por ato próprio (decreto), cria a empresa estatal. Os estatutos da entidade deverão ser registrados, pois é o registro que dá nascimento à pessoa jurídica, e não a lei, ao contrário do que ocorre, por exemplo, com a autarquia (MOURA DE ANDRADE, 2007, p. 68).

Importante ressaltar que a Constituição de 1988, disciplina que as empresas públicas não poderão gozar de privilégios fiscais frente às empresas privadas, ou seja, o capital deve ser fechado sem participação do setor privado. Entretanto, as empresas públicas podem ser beneficiárias de capital dos entes da Administração Pública direta. 
Empresas públicas são pessoas jurídicas de direito privado, criadas por autorização legislativa, com totalidade de capital público e regime organização livre. Exemplos: Banco Nacional de desenvolvimento Econômico e Social - BNDS, Empresa Brasileira de Correios e Telégrafos - ECT, Caixa Econômica Federal - CEF, Empresa Brasileira de Pesquisa Agropecuária - Embrapa e Empresa Brasileira de Infraestrutura Aeroportuária - Infraero. O conceito legislativo está previsto no art $5^{\circ}$, II, do Decreto-Lei $\mathrm{n}^{\circ}$ 200/67: empresas públicas são entidades públicas dotadas de personalidade jurídica de direito privado, com patrimônio próprio e capital exclusivo da União, criadas por lei para exploração de atividade econômica que o Governo seja levado a exercer por força de contingência, ou de conveniência administrativa, podendo revestir-se de quaisquer das formas admitidas em direito (MAZZA, 2015, p. 200).

Nesse sentido, a forma empresarial a ser adotadas pelas empresas públicas é livre, portanto, pode ser sociedade anônima, comandita por ações, dentre outras; possuem autonomia administrativa, autonomia financeira e patrimônio próprio. Todavia, caso a entidade seja prestadora de serviços públicos, os bens vinculados à atividade fim não se sujeitam a qualquer tipo de oneração, salvo determinação legal.

Ademais, caso a maioria do capital permaneça em propriedade dos entes públicos da Administração pública direta, será admitido, no capital da empresa pública a sua respectiva participação. Nesse passo, a empresa pública deverá observar os princípios expressos do artigo $37^{\circ}$ da Constituição Federal para consecução de suas atividades, quais sejam: legalidade, impessoalidade, moralidade, publicidade e eficiência, na medida no regime híbrido as normas de direito público se sobrepõem as normas de direito privado.

Há que se atentar que as empresas públicas têm o dever de licitar nos casos de exploração de atividade econômica e prestação de serviço, vez que a lei ao definir o estatuto próprio deverá dispor sobre licitação e contratação nas estatais.

A Emenda Constitucional $\mathrm{n}^{0} 19 / 98$ trouxe alguma alteração na matéria de licitação e contrato referente às empresas públicas e sociedade de economia mista. Isto porque, ao alterar a redação do artigo 22, XXVII, fez remissão, com relação a tais entidades, ao artigo $173, \S 1^{\circ}$, III; segundo esse dispositivo, a lei que definir o 
estatuto jurídico da empresa pública, da sociedade de economia mista e das subsidiárias que explorem atividade econômica de produção ou comercialização de bens ou de prestação de serviços disporá sobre "licitação e contratação de obras, serviços, compras e alienações, observados os princípios da administração pública" (DI PIETRO, 2011, p. 468-469).

Nesse sentido, a Constituição Federação no artigo $173 \S^{\circ}$, III determina que a lei ao estabelecer o estatuto próprio das empresas públicas nos casos de exploração de atividade econômica ou comercialização de bens deverá dispor sobre contratação e licitação, entretanto, caso não seja elaborado o estatuto jurídico aplicar-se-á o dispositivo da Lei no 8.666/93.

Quanto à admissão de agentes nas empresas públicas o acesso ao emprego é por via de concurso público, sendo regido pela Consolidação das Leis do Trabalho, porém, os agentes não podem cumular cargos, pois são equiparados aos servidores públicos, quanto à dispensa deverá ser motivada, conforme os princípios da Administração Pública.

A Professora Flávia Cristina Moura de Andrade explica que também existe impossibilidade de acumulação de cargos de seus servidores (Art. 37, XVI e XVII, CF/88, e a sujeição ao teto de remuneração se receber recursos

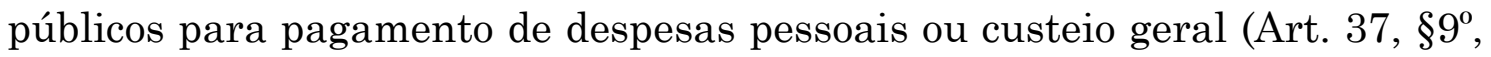
CF/88) (Moura de Andrade, 2007, p. 72).

Vale ressaltar que a extinção da empresa pública submete-se ao mesmo procedimento de criação, ou seja, autorização por lei de iniciativa do Executivo; decreto regulamentando a extinção, e baixa dos atos constitutivos no cartório, sendo que eventuais litígios trabalhistas serão julgados na justiça do Trabalho e caso haja interesse da União caberá à justiça Federal julgar.

A partir da análise da estrutura o Departamento de Coordenação e Governança das Empresas Estatais (DEST), Órgão responsável pelas Empresas Estatais Federais constatou que ao final do ano de 2013 houve uma evolução no número de empresas públicas no país. Segundo o Órgão nos últimos cinco anos foram analisados 141 estatais em pleno 
funcionamento, sendo que 48 são controladas diretamente pela União, e as outras 93 são controladas de modo indireto.

Conforme os dados disponibilizados pelo DEST às empresas públicas estão distribuídos por área de atuação, administração aeroportuária 1\%, desenvolvimento regional $1 \%$, comunicação $2 \%$, minas e metalúrgica $2 \%$, indústria de transformação $3 \%$, pesquisa e desenvolvimento $3 \%$, saúde e assistência social $3 \%$, transporte $3 \%$, abastecimento $3 \%$, portuário $5 \%$, comércio e serviço $11 \%$, setor financeiro 13\%, energia elétrica $23 \%$ e petróleo e derivados $27 \%$.

Outrossim, o órgão responsável pelas Empresas Estatais alerta sobre a evolução do número de empregados no setor produtivo e no setor financeiro, vez que o quadro pessoal das empresas públicas constatou o crescimento de cerca 550 mil empregados ao longo dos últimos cinco anos.

As empresas ligadas ao setor de energia, o que inclui o setor petrolífero, compõem a maioria das empresas listadas entre as de maiores receitas líquidas, lucro líquido, ativos, recursos de terceiros, patrimônio líquido e, também, de prejuízos no ano de 2013 (DEST, 2013, p. 22).

Nesse sentido, o DEST divulgou o ranking das 10 maiores empresas pertencente ao Setor Produtivo com o maior número de ativo: $1^{\circ}$ Petrobrás, $2^{\circ}$ Eletrobrás, $3^{\circ}$ PNBV, $4^{\circ}$ PIFCO, $5^{\circ}$ PIB BV, $6^{\circ}$ TAG, $7^{\circ}$ Furnas, $8^{\circ}$ Pai, $9^{\circ}$ Eletronorte e $10^{\circ} \mathrm{BR}$.

Entre as dez empresas que registraram maior lucro líquido em 2013, sete são do Grupo Petrobras. Na lista das dez empresas que registraram maior prejuízo em 2013, a controladora do Grupo Eletrobrás apresentou o maior prejuízo, seguida por algumas de suas subsidiárias: AME, FURNAS, ELETRONUCLEAR, CGTEE e CHESF. Segundo a controladora, o desempenho do exercício 2013 ainda refletiu as novas tarifas de geração e transmissão, cujas concessões foram renovadas nos termos da Lei 12.783/13, além de outras variáveis não recorrentes, tais como aumento das despesas relacionadas ao Plano de Incentivo ao Desligamento de Empregados (PID), Provisão para Contingências e Impairment 10. 10 Redução ao Valor Recuperável de Ativos. SETOR PRODUTIVO PERFIL DAS EMPRESAS ESTATAIS FEDERAIS - ANO BASE 201323 A ECT continua mantendo o posto de maior empregadora entre as empresas do Setor Produtivo, seguida pela PETROBRAS (DEST, 2013, p. 22-23). 
Para desenvolver essas pesquisas o Departamento de Coordenação e Governança das Empresas Estatais adotou os seguintes critérios: total de ativo, ativo imobilizado, recursos de terceiros, patrimônio líquido, receita líquida, lucro líquido, prejuízos e quadro pessoal de empregado dos últimos cinco anos de atividade das empresas públicas.

Diante disso, se constata que o estudo das empresas públicas relaciona-se com a forma de organização administrativa do Estado, assunto de extrema importância para compreensão da estrutura da Administração Pública, seja ela direta e indireta, desconcentrada e descentralizada correspondente à atividade estatal.

\section{Evolução histórica dos programas compliance de anticorrupção}

Constata-se que durante as investigações do chamado caso Watergate surgiu evidências de pagamentos ilegais de empresas privadas aos políticos para patrocinar as campanhas eleitorais nos Estados Unidos. Diante disso, a Securities and Exchange Commission (SEC) iniciou uma serie de investigações para apurar irregularidades nos pagamentos e doações realizadas aos políticos nacionais. Não obstante, a SEC acabou descobrindo fundo secreto destinado aos políticos, às autoridades públicas e as empresas de outros países.

Igualmente, na década de 70 foram desvelados, que diversas empresas americanas incorreram em atos de corrupção junto aos funcionários públicos estatais e representantes de governos estrangeiros, com objetivo de obterem e reterem vantagem ilícita nos negócios.

Historicamente, no entanto, é preciso assinalar que o combate à corrupção no mundo teve início no setor privado e não no setor público. A "Securities and Exchange Commission" norte americana, na década de 70 da centúria passada, elaborou estudos relativos a subornos pagos por empresas estadunidenses a funcionários 
públicos estrangeiros com o fito de obterem vantagens sobre empresas concorrentes (DE LUCCA, 2009, p. 337-338).

Os diversos escândalos envolvendo grandes empresas do setor privado com servidores públicos impulsionaram o Congresso dos Estados Unidos em 1977 editar o Foreign Corrupt Practices Act (FCPA), a denominada Lei América Anticorrupção no Exterior, com a finalidade de aplicar sanções administrativas, comerciais, cíveis e penais para combater os atos de corrupção na esfera empresarial e administrativa.

A FCPA abrange pagamentos feitos diretamente pela empresa e indiretamente por meio de um intermediário, como por exemplo, parceiros de negócio. Pagamentos ilegais podem incluir pagamentos a título de corrupção feitos para conseguir ou manter contratos governamentais ou pagamentos feitos para obter qualquer outro benefício de um funcionário do governo, como por exemplo, redução de impostos, aprovação legal, alteração da lei ou o recebimento de autorizações necessárias (QUALICORP).

O objetivo da FCPA foi de restabelecer a credibilidade da atuação das empresas americanas no exterior, bem como recuperar a confiança e a integridade financeira no funcionamento eficiente do mercado, além de resgatar a liderança no cenário internacional.

A aplicação da lei americana anticorrupção no exterior envolve os seguintes Órgãos no combate aos atos de corrupções: Department of Justice American (D.O.J), a qual tem a finalidade de fiscalizar o cumprimento da lei, e a Securities and Exchange Commission (SEC), Órgão responsável pela coordenação da FCPA nos Estados Unidos.

Creio que a SEC esteja se movendo em direção a um padrão de responsabilidade objetiva para os controles internos sob o FCPA. Isto significa que se o seu regime de controles internos de compliance estiver sendo investigado, você terá que demonstrar que cumpre alguns padrões mínimos que satisfaçam a SEC. Se não, a SEC poderá iniciar um processo administrativo contra sua companhia, alegando falhas em manter controles internos adequados exigidos pelo FCPA e sua empresa arcará com o ônus da prova de demonstrar que efetivamente projetou e implementou um sistema eficaz de controles internos (FOX, CARRIL, 2015). 
Nota-se que o objetivo comum da Securities and Exchange Commission (SEC) e do Department of Justice American (D.O.J) foi de atribuir-se responsabilização objetiva às pessoas físicas ou jurídicas que praticarem atos de corrupção, considerando os requisitos da Foreign Corrupt Practices Act (FCPA), vez que a lei não obriga às empresas implementarem controles internos de prevenção - anticorrupção, apesar de se tratar de um modelo imprescindível às empresas.

Nesse sentido, Lanny A. Breuer, Procurador-Geral Adjunto do Departamento de Justiça Norte Americano (D.O.J.) argumenta que a "aplicação da FCPA é fundamental para proteger a integridade dos mercados para as empresas americanas de fazer negócios no exterior, e vamos continuar a deixar claro que subornar funcionários estrangeiros não é um atalho aceitável.".

Outrossim, Robert Khuzami, Diretor da Divisão de Execução da Comissão de Títulos e Câmbio dos Estados Unidos argumenta que "os investidores devem ter fé que o desempenho económico das empresas públicas reflete considerações legais de mercados, preços e produtos, em vez de uma miragem resultante de suborno e corrupção".

Desse modo, é evidente que a aplicação do Foreign Corrupt Practices Act continua sendo essencial no combate ao abuso de poder, corrupção e no suborno praticado por empresas, autoridades, políticos e servidores públicos nos Estados Unidos. Entretanto, é importante ressaltar-se que os preceitos de eficácia da FCPA tornaram-se referência de modelo em diversos países, que por sua vez implantam medidas de combate à corrupção.

Umas das medidas criadas pela Foreign Corrupt Practices Act foram os programas compliance anticorrupção nas empresas. Os programas compliance deriva do verbo Inglês to comply, na tradução livre significa conformidade legal, ou seja, execução de medidas de comprometimento das empresas no combate à corrupção. 
Para Newton de Lucca, compliance - ou conformidade legal -, em primeiro lugar, é a adoção de um código de ética interno. O compliance determina e estimula não apenas as práticas de conformidade com os comandos legais quanto os comportamentos da sociedade em geral (DE LUCCA, 2009, p. 377).

Os programas compliance são fundamentais no combate à corrupção, haja vista os diversos escândalos de cunho moral envolvendo grandes empresas ao longo da história, tais como: WorldCom, Enron, Tyco, Beacon Hill, Samsung, Vale, Petrobras, JBS-Friboi, dentre outras organizações.

Impõe-se esclarecer que os programas compliance contribui para a governança corporativa, vez que objetiva mitigar os riscos da atividade empresarial. Entretanto, para que os programas compliance sejam bemsucedidos é necessário que seja aplicável a todos os funcionários da empresa, incluindo o gestor da organização - CEO.

\footnotetext{
"Compliance é muito mais do que garantir a assinatura de um papel. Muitas vezes o funcionário nem lê a política. E a verdade é que ninguém muda uma cultura simplesmente fazendo alguém assinar um papel. Os funcionários se guiam muito pelo que elas dizem". Outra frase deveras expressiva de Joseph E. Murphy nessa mesma entrevista é a seguinte: "Um item essencial nesse campo é que a chefia seja responsável também. Se alguém é pego por contravenção às regras da companhia, é importante que não só essa pessoa seja punida, mas também o seu chefe, que é responsável pela disciplina da equipe. (DE LUCCA, 2009, p. 377).
}

Observa-se, que o compliance deve ser aplicáveis a todos envolvidos na atividade empresarial, sendo que não basta à mera criação de código de ética, código de conduta e auditoria interna, é necessária a responsabilização da pessoa envolvida com atos ilícitos, pois conforme prevê a legislação dos Estados Unidos às medidas anticorrupção devem estar integralizadas aos controles internos da empresa.

Nesse passo, Manzi afirma que diante de novas exigências do mercado de transparência, disciplina e aprimoramento dos controles internos, não é 
possível falar em governança corporativa sem relacionar à gestão de riscos, inclusive risco de compliance (MANZI, 2008, p.70).

Observa-se que, diante dos princípios da FCPA, caberá ao conselho de administração proferir decisões punitivas, bem como desenvolver canal de ouvidoria funcional no âmbito interno da empresa para que os funcionários possam realizar denúncias que envolvam riscos operacionais, pois sem ética não há governança corporativa e nem eficiência dos programas compliance que foi implantado na organização.

Conforme visto, o Foreign Corrupt Practices Act (FCPA) criada em 1977 desenvolveu medidas efetivas e inovadoras de combate à corrupção nas empresas privadas, consoante a sua atividade econômico atrelado à moralidade e a ética empresarial.

Seguindo os preceitos da Lei Federal Norte Americana Antissuborno diversas normas e tratados anticorrupção foram criados pela comunidade internacional, tais como: Organização dos Estados Americanos (OEA) Convenção Interamericana contra a Corrupção em 1996; Organização para a Cooperação e Desenvolvimento Econômico (OCDE) - Convenção sobre Combate à Corrupção de Funcionários Públicos Estrangeiros em Transações Comerciais Internacionais; e a Organização das Nações Unidas (ONU) Convenção das Nações Unidas contra Corrupção em 2003.

\footnotetext{
E nesse contexto mundial de práticas de corrupção extraterritorial, o nosso país se comprometeu a responsabilizar as pessoas jurídicas corruptoras, ao ratificar: (i) a Convenção sobre o Combate da Corrupção de Funcionários Públicos Estrangeiros em Transações Comerciais Internacionais, da Organização para a Cooperação e o Desenvolvimentos Econômico - OCDE, de 1997, mediante o Decreto n. 3.678, de 2000; (ii) A Convenção Interamericana contra a Corrupção, da Organização dos Estados Americanos (OEA) DE 1996, mediante o Decreto ${ }^{\circ}$ 4.410, de 2002 e a (iii) a Convenção das Nações Unidas contra a Corrupção, de 2003, mediante o Decreto n. 5.687, de 2006 (CARVALHOSA, 2015, p. 103).
}

Com efeito, diversos países também criaram legislações anticorrupção, destaca-se a UK Bribery Act - UKBA (Lei de Suborno do 
Reino Unido) adotada em 2010, a qual prevê a responsabilidade objetiva no âmbito civil e administrativo da pessoa jurídica que praticar os atos destacados de corrupção, tais como: corrupção ativo ou passivo envolvendo os sujeitos públicos ou privados; corrupção de agentes públicos estrangeiros, folha as empresas na prevenção da corrupção, verifica-se que o foco da Lei do Reino Unido é na prevenção do delito.

Igualmente, a França instituiu em 2007 penalidades severas para as pessoas físicas e jurídicas que incorrem em atos de corrupção. Entretanto, somente as empresas francesas podem sofrer sanção na França se o crime tiver sido cometido por sua subsidiária em país estrangeiro.

Frente aos preceitos do Foreign Corrupt Practices Act o Brasil também editou leis de combate à corrupção, tais como a Lei Federal $\mathrm{n}^{\circ}$ 10.467/2002 - Crimes de ocultação de bens, a qual prevê a tipificação do crime de corrupção ativa em transação comercial internacional, bem como do tráfico de influência em transação comercial internacional. Outrossim, a Lei Federal $n^{\circ} 10.763 / 2003$ acrescenta artigo ao Código Penal e modifica a pena cominada aos crimes de corrupção ativa e passiva.

Para Carvalhosa, não cabe mais falar apenas em corrupção como fenômeno nacional que, portanto, pudesse ser analisado e dimensionado em cada país, sem levar em conta a globalização das economias e, nela, a prevalência das multinacionais (CARVALHOSA, 2015, p.99).

Nesse passo, é possível afirmar que houve uma disseminação legislativa na comunidade internacional sobre a gestão dos bens e recursos públicos, haja vista os grandes escândalos de corrupção envolvendo grandes empresas que operam em diversos países.

\section{Do desenvolvimento e implantação dos programas compliance}

\section{nas empresas públicas brasileiras}


Após as manifestações ocorridas em julho de 2013 em diversas capitais no Brasil, o tema da corrupção passa a ocupar ainda mais espaço na mídia e as autoridades passaram a sofrer pressão popular para criação de medidas concreta de combate a corrução.

Diante das manifestações ocorridas naquele ano alguns projetos associados ao tema de corrupção são aprovados pelo Congresso Nacional Brasileiro, entre os quais a Lei Anticorrupção, Lei $\mathrm{n}^{0} 12.846$, de $1^{\circ}$ de agosto de 2013. Tendo em vista as pressões vindas das ruas, a lei brasileira tem seu escopo estendido, além de atingir a prática de corrupção no exterior, se aplica também aos atos de corrupção praticados dentro do país.

Com efeito, a lei anticorrupção vem somar-se a disposições contidas em diversas outras leis, sem uma preocupação de sistematização; tais como: a Lei Geral de Licitações, Lei de Improbidade Administrativa, Sistema Brasileiro de Defesa da Concorrência, Lei da Ação Civil Pública, Código Penal, dentre outros dispositivos.

Cumpre informar que a Lei Federal n 12.846/2013 não criou novos tipos penais, mas sim dispõe sobre a responsabilidade civil e administrativa dos gestores e das pessoas jurídicas que cometerem os atos de corrupção previstos nesta lei, não apenas corrupção, como também fraude à licitação.

Outrossim, a lei anticorrupção apresenta rol genérico e abrangente de atos lesivos a Administração Pública, seja nacional ou estrangeira, ainda criou a figura da responsabilidade objetiva das pessoas jurídicas, além de conter descrição de tipos infracionais muito genéricos, algumas das ações descritas são essencialmente iguais a tipos penais já existentes.

Entretanto, a grande inovação da Lei $\mathrm{n}^{0} 12.846 / 2013$ foi à possibilidade das empresas implantarem os programas compliance através da existência de mecanismo e procedimentos internos de integridade, auditoria interna, incentivo a denúncia de irregularidades e aplicação efetiva de códigos de ética e de conduta no âmbito da pessoa jurídica. 
Os programas e as medidas concretas tomadas pelas pessoas jurídicas visando criar, incentivar e efetivar métodos de conformidade das suas atividades com as exigências legais e regulamentares emanadas pelo Estado incluem as práticas relacionadas com a moralidade da conduta profissional dos integrantes de seus quadros - dirigentes e empregados. Essas práticas compreendem os relacionamentos da pessoa jurídica (i) internos; (ii) com outras pessoas jurídicas; e (iii) com o Estado (CARVALHOSA, 2015, p. 2015).

Desse modo, as empresas podem implantar políticas de prevenção à corrupção; adequação às regras e leis; elaboração do Código de ética e de Conduta; edição de regras de comportamento institucional; controle interno e treinamento pessoal; canais para recebimento de denúncia; criação de auditoria interna e de um comitê permanente.

Verifica-se que o objetivo dos programas compliance é evitar os riscos da atividade empresarial, bem como de punir a pessoa jurídica que praticar atos de corrupção, pois os atos de corrupção praticados por pessoas físicas no ambiente interno e externo da empresa podem acarretar responsabilidade objetiva da pessoa jurídica, seja na esfera civil, penal e administrativa, uma vez que os atos ilícitos praticados por funcionários, ou pelo gestor da organização - CEO independe de culpa.

\begin{abstract}
Atualmente, além das repercussões criminais, a corrupção também pode ser considerada um ato contra a Administração Pública nacional ou estrangeira, sendo que a lei anticorrupção (Lei 12.846/2013) surgiu da percepção de que, para controlar a corrupção, seria necessário conjugar esforço, não apenas do governo, mas também das empresas, promovendo um ambiente de integridade que abarcasse o relacionamento da esfera pública com a esfera particular. Discute-se, ainda, por anteprojetos capitaneados por membros do Ministério Público Federal, meios para tornar mais efetivo o combate à corrupção no Brasil (NOHARA, 2016, p. 93).
\end{abstract}

Constata-se que a Lei $\mathrm{n}^{0}$ 12.846/2013, também conhecida como lei anticorrupção surgiu para mitigar os atos de corrupção nas empresas privadas que realizam negócios com funcionários ou autoridades públicas, 
pois a corrupção pode ocasionar diversos danos ao patrimônio da Administração Pública nacional ou estrangeira.

Diante da eficácia da Lei $\mathrm{n}^{0} 12.846 / 2013$ o Congresso Nacional aprovou a Lei $\mathrm{n}^{0} 13.303 / 2016$, na qual possibilita as empresas públicas implantarem programas compliance, observando as regras de governança corporativa, de transparência, de estrutura, práticas de gestão de risco e controle interno, uma vez que se trata de mecanismo de prevenção de atos ilícitos que envolvem bens públicos.

Uma das novidades da lei anticorrupção das empresas públicas são os mecanismos de transparência empresarial, pois as estatais deverão divulgar de forma tempestiva e atualizada as informações relevantes de gestão, em especial as relativas a atividades desenvolvidas, estrutura de controle, fatores de risco, dados econômico-financeiros, comentários dos administradores sobre o desempenho, políticas e práticas de governança corporativa e descrição da composição e da remuneração da administração pública, com a finalidade de evitar que determinadas autoridades públicas incorrem em atos de corrupção.

\footnotetext{
Um fator que foge à discussão jurídica da realização da supremacia dos interesses públicos, mas que tem um impacto prático significativo é a corrupção. De nada adianta o Estado criar instituições e reforçá-las para que expressem os interesses da coletividade, dentro dos valores pluralistas da sociedade democrática, se, no final das contas, o que determina a palavra final de algumas autoridades públicas corruptas for estabelecido por meio de vantagens recíprocas que são repartidas num esquema de espoliação pública (NOHARA, 2016, p. 93).
}

Percebe-se que a Lei 13.303/2016 possui a finalidade de evitar desvio de recursos públicos nas empresas públicas. Desse modo, as estatais deverão elaborar e divulgar políticas públicas de transações com partes relacionadas à atividade empresarial em conformidade com os requisitos de competitividade, conformidade, transparência, equidade e comutatividade, 
que deverá ser revista pelo conselho de administração no prazo mínimo de um ano.

Diante das repercussões de grandes escândalos envolvendo empresas públicas a lei anticorrupção recomenda que as estatais divulguem seu custo e suas receitas discriminadas, incluindo o plano contábil, ao público em geral, seguindo os preceitos de governança corporativa.

\footnotetext{
$\mathrm{Na}$ realidade, diversas Administrações Públicas dos países ocidentais passaram no término do século XX por uma onda de transformação de suas estruturas burocráticas com base na New Public Management, que influenciou o vocabulário da gestão pública com noções da governança corporativa (NOHARA, 2016, p. 2016).
}

Seguindo os preceitos da Lei $n^{0} 12.846 / 2013$ a nova disposição legal das empresas públicas recomenda que as estatais implantarem regras de estruturas e práticas de gestão de riscos e controle interno, tais como: auditoria interna e comitê de auditoria estatutário; elaboração de código de ética e integridade; canal de denúncias que possibilite o recebimento de denúncias internas relativas ao descumprimento do código de conduta e integridade, sem prejuízo das normas éticas para evitar atos de corrupção e fraude no âmbito interno e externo das empresas públicas.

Outro ponto central da Lei $n^{0} 13.303 / 2016$ é a transparência melhor disciplinada, pois as empresas públicas deverão divulgar toda e qualquer remuneração dos administradores, bem como adequar de forma contínua os atos empresariais ao código de conduta e integridade e as regras de governança corporativa, vez que os presentes mecanismos passaram a ser maior utilizado na comunidade internacional, pois a governança corporativa dispõe de fatores de responsabilização dos gestores de empresas, seja ela pública ou privada.

Contudo, a grande inovação da lei anticorrupção das empresas públicas foi à possibilidade do estatuto social de prever a área de compliance independente, a qual possibilita a criação de conselho de administração para 
investigar o diretor ou presidente da estatal envolvido com irregularidades ou atos de corruptivos.

No entanto, para que os programas compliance desenvolvidos e implementados pelas empresas públicas se tornem eficientes é necessário que o comitê da área seja independente e tenha uma estrutura permanente. Ademais, o processo de seleção de membros que irão compor o comitê da área de compliance deverá ser democrático, ou seja, tanto os profissionais da alta administração, bem como os profissionais operacionais devem participar do processo seletivo, a fim de desenvolver políticas de compliance no âmbito da empresa pública.

As atividades do comitê de compliance são gerenciar as atividades de risco da empresa, através de elaboração de código ou manual de compliance, a fim de combater atos de corruptivos no âmbito interno e externo da empresa, tais como: suborno, propina e lavagem de dinheiro. Além disso, o comitê deve criar um canal de denúncias, com a finalidade de responsabilizar os desvios de conduta dos profissionais.

Observe que o objetivo dos programas compliance não é apenas auxiliar os demais controles da empresa pública, mas também é conscientizar e orientar os profissionais desenvolverem as atividades com prudência, sempre pautadas nos valores éticos e morais, a fim de evitar condutas que possam ocasionar riscos e prejuízos à organização.

Em suma, é possível verificar que os objetivos gerais da Lei $n^{\circ}$ 13.303/2016 é proteger funcionários, colaboradores, gestores, controladores e acionistas, ou seja, todos os envolvidos com risco da atividade empresarial na esfera da Administração Pública, seja ela direta ou indireta, desconcentrada e descentralizada, a fim de se evitar prejuízo à coisa pública.

\section{Considerações finais}

A Constituição Federal de 1998 consagrou às pessoas jurídicas de direito privado no âmbito da Administração Pública indireta a expressão 
empresas estatais, cujo Estado possua o controle acionário. Vale ressaltar que a expressão alcança as empresas públicas, apesar da personalidade de direito privado.

Desse modo, pode se dizer que empresas públicas são entidades dotadas de personalidade jurídica de direito privado, a qual possui o patrimônio próprio com capital exclusivo do Estado, com o objetivo de prestar serviço público, bem como exploração da atividade econômica, sendo concebidas por lei específica.

Essa conjuntura permitiu o Departamento de Coordenação e Governança das Empresas Estatais (DEST) Órgão responsável pelas Empresas Estatais Federais verificar que ao final do ano de 2013 houve uma evolução no número de empresas públicas no Brasil. Segundo o órgão nos últimos cinco anos foram analisados 141 estatais em pleno funcionamento, sendo que 48 são controladas diretamente pela União, e as outras 93 são controladas de modo indireto pelo Estado.

Por outro lado, as repercussões de corrupção envolvendo empresas privadas com funcionários públicos impulsionou a edição da Lei $\mathrm{n}^{\circ}$ 12.846/2013, a denominada lei anticorrupção, criada com a finalidade de mitigar os atos ilícitos através dos programas compliance, pois a corrupção ocasionou diversos danos ao patrimônio da Administração Pública nacional e estrangeira.

Seguindo os preceitos da lei anticorrupção foi editada a Lei $n^{\circ}$ 13.303/2016, a qual possibilitou às empresas públicas também desenvolverem e implantarem programas compliance, em consonância com os princípios da Administração Pública, bem como os mecanismos de prevenção de atos ilícitos, tais como as regras de governança corporativa, estrutura, práticas de gestão de risco e controle interno.

Em vigor, uma das novidades da lei anticorrupção das empresas públicas são os mecanismos de transparência empresarial, pois as estatais deverão divulgar de forma tempestiva e atualizada as informações 
relevantes de gestão, em especial as relativas a atividades desenvolvidas, estrutura de controle, fatores de risco, dados econômico-financeiros, comentários dos administradores sobre o desempenho da empresa, políticas e práticas de governança corporativa, descrição da composição do conselho e remuneração da Administração Pública, com a finalidade de evitar que determinados agentes do Poder Público incorram em atos de corrupção.

Igualmente, a lei anticorrupção recomendou que as estatais divulgassem seus custos e suas receitas discriminadas, incluindo o plano contábil, ao público em geral, seguindo os preceitos de governança corporativa. No entanto, a grande inovação da lei anticorrupção das empresas públicas foi à possibilidade do estatuto social de prever a área de compliance independente, a qual possibilita o conselho de administração investigar o diretor ou presidente da estatal envolvido com irregularidades ou com atos de corrupção.

Verifica-se, portanto, que a finalidade da à Lei $\mathrm{n}^{0} 13.303$ de 2016 é evitar os riscos da atividade empresarial na Administração Pública, bem como de punir a pessoa jurídica que praticar atos de corrupção, pois o ato de corrupção praticado por pessoas físicas no ambiente interno e externo da empresa acarreta na responsabilidade objetiva da pessoa jurídica, seja na esfera civil, penal e administrativa, vez que os atos ilícitos praticados por funcionários públicos, gestores e diretores independem de culpa.

\section{Referências}

BRASIL. Constituição Federal de 1998.

BRASIL. Lei $\mathrm{n}^{\circ} \mathbf{1 2 . 8 4 6}$ de 2013.

BRASIL. Lei $\mathrm{n}^{\circ} 13.303$ de 2016.

BRASIL. Lei ${ }^{\circ} 8.666$ de1993.

CARVAlHOSA, Modesto. Considerações Sobre a Lei Anticorrupção das Pessoas Jurídicas. São Paulo: Revista dos Tribunais, 2015.

DE LUCCA. Newton. Da Ética Geral à Ética Empresarial. São Paulo: Quartier Latin, 2009.

DI PIETRO, Maria Sylvia Zanella. Direito administrativo. São Paulo: Atlas, 2011.

HABERMAS, Jurgen. Mudança Estrutural da Esfera Pública. Tradução: Denílson Luís Werle. São Paulo: Unesp, 2011. 
DEST, Departamento De Coordenação e Governança das Empresas Estatais. Perfil das Empresas Estatais Federais 2014 - Ano Base 2013. Brasília: DEST, 2015.

FOX, Thomas. A responsabilidade objetiva estaria se aproximando da aplicação do FCPA. Traduzido por Rodrigo Coutinho Carril. São Paulo: ICB, 2015.

MAURA DE ANDRADE, Flávia Cristina Moura. Elementos de Direito Administrativo. São Paulo: Premier Máxima, 2007.

MAZZA, Alexandre. Manual de Direito Administrativo. São Paulo: Saraiva, 2015.

MAZZI, Vanessa Alessi Manzi. Compliance no Brasil. São Paulo: Saint Paul, 2008.

NOHARA, Irene Patrícia. Fundamentos de Direito Público. São Paulo: Atlas, 2016. Gestão Pública dos Entes Federativos. São Paulo: Clássica, 2013.

Direito administrativo. São Paulo: Atlas, 2015.

QUALICORP. Manual Anticorrupção \& FCPA. São Paulo: QUALICORP, 2015.

Artigo recebido em: 14/02/2019.

Aceito para publicação em: 19/11/2019. 